\title{
Radiosensitization by Radiofrequency Fields is Correlated with Micronucleus Yield and Proliferative Index
}

\author{
Angela Chinhengo, Antonio Serafin, \& John Akudugu* \\ Division of Radiobiology, Department of Medical Imaging and Clinical Oncology, Faculty of \\ Medicine and Health Sciences, Stellenbosch University, South Africa \\ *Address all correspondence to: John Akudugu, Division of Radiobiology, Department of Medical Imaging and \\ Clinical Oncology, Faculty of Medicine and Health Sciences, Stellenbosch University, Tygerberg 7505, South Africa; \\ Tel.: +27-21-938-9942, E-mail: jakudugu@sun.ac.za
}

\begin{abstract}
Radiofrequency fields have been shown to potentiate the inactivating effects of ionizing radiation. Using four human cell lines: MeWo (melanoma), Be11 (melanoma), DU145 (prostate cancer), and L132 (normal lung fibroblasts), it is demonstrated that cellular radiosensitization by $100-$ and $1000-\mathrm{Hz}$ amplitude modulated radiofrequency fields is correlated with micronucleus yield (DNA damage) and binucleation index (proliferation). Cells that were more radiosensitized by radiofrequency fields were found to show increased levels of micronucleus yield. A high level of radiosensitization by the $100-\mathrm{Hz}$ modulated field was correlated with increased proliferative index, while an elevated binucleation index was linked to minimal radiosensitization by the $1000-\mathrm{Hz}$ modulated field. These findings suggest that radiofrequency fields can interfere with cellular processing of ionizing radiation-induced DNA damage and cell cycle progression, and may have significant implications in radiotherapy, radiation protection, and wound healing in preoperative radiotherapy.
\end{abstract}

KEY WORDS: radiofrequency fields, micronucleus yield, proliferation, radiotherapy

\section{INTRODUCTION}

The biological effects of radiofrequency fields (RFF) are varied, and may be categorized as genotoxic (e.g., chromosomal aberration, micronucleus formation) and nongenotoxic (e.g., cell proliferation). ${ }^{1}$ For medical and research purposes, radiofrequencies are generated by amplitude modulating a carrier frequency of $\sim 27.12 \mathrm{MHz}$. The antitumor effects of radiofrequency fields have been attributed to a unique phenomenon of the existence of tumor-specific modulating frequencies, whereby fields modulated by certain frequencies only exert their effects on particular tumors. ${ }^{2-4}$ Radiofrequency tumor ablation, mediated by this phenomenon, is correlated with the dielectric property of the tumor in question and, thus, its water content. ${ }^{5,6}$

Treatment of patients with advanced hepatocellular carcinoma with modulating frequencies ranging from $100 \mathrm{~Hz}$ to $21 \mathrm{kHz}$ yielded positive results. ${ }^{7}$ Barbault and colleagues treated 163 patients for 15 cancers with modulating frequencies of $100 \mathrm{~Hz}-114$ $\mathrm{kHz}$ and noted that the most common specific frequencies for breast cancer, hepatocellular carcinoma, prostate cancer, and pancreatic cancer were 1873.477, 2221.323, 6350.333, and 10,456.383 Hz, respectively. ${ }^{8}$ Frequency-dependent antiproliferative 
effects were also demonstrated in hepatocellular carcinoma and breast cancer cells, but not in normal cells. ${ }^{9}$

The selectivity of radiofrequencies in negatively affecting only malignant cells could be harnessed for more effective cancer management. However, unlike for electric and magnetic fields, studies investigating the combined effects of radiofrequency fields and chemotherapeutic drugs or ionizing radiation are virtually nonexistent. A couple of studies using fibroblasts and melanoma cells showed that RFF can act either as radiosensitizers or radioprotectors. ${ }^{10,11} \mathrm{An}$ insight into the factors that influence these modifying effects of RFF could have significant implications in radiotherapy and radiation protection settings.

The aim of this study was to evaluate the effect of RFF exposure on ionizing radiation-induced genotoxic and nongenotoxic responses, using the cytokinesis-block micronucleus formation and binucleation assays, respectively. For this, human melanoma and prostate cancer cells as well as normal lung fibroblasts were assessed. The relationship between RFF-induced changes in radiosensitivity and radiation-induced DNA damage and proliferative responses is also discussed.

\section{MATERIALS AND METHODS}

\section{A. Cell Lines and Culture Maintenance}

The cell lines used were human melanomas (MeWo and Be11), prostate carcinoma (DU145), and normal lung fibroblasts (L132). The MeWo, Be11, and DU145 cells were cultured in minimum essential medium (MEM), and the L132 cells were maintained in Roswell Park Memorial Institute medium (RPMI). The cells were routinely grown as monolayers in $75-\mathrm{cm}^{2}$ flasks, supplemented with $10 \%$ fetal bovine serum $(20 \%$ for the MeWo cells) and $1 \%$ penicillin-streptomycin, and incubated at $37^{\circ} \mathrm{C}$ in a humidified atmosphere ( $95 \%$ air, $5 \% \mathrm{CO}_{2}$ ), and were used for experiments at $80-90 \%$ confluence. For clonogenic cell survival, cells were trypsinized, counted, and plated in $25-\mathrm{cm}^{2}$ culture flasks prior to treatment. Exponentially growing cells in $25-\mathrm{cm}^{2}$ flasks were treated to trypsinization into single-cell suspensions for the micronucleus and binucleation assays.

\section{B. X-Ray Irradiation and Radiofrequency Field Exposure}

For cell survival, appropriately prepared cell cultures were irradiated at room temperature $\left(20^{\circ} \mathrm{C}\right)$ to $2 \mathrm{~Gy}$, at a dose rate of $1.0 \mathrm{~Gy} / \mathrm{min}$, using a Precision MultiRad 160 $\mathrm{X}$-irradiator (Precision X-Ray Inc., Branford, CT, USA), $2 \mathrm{~h}$ prior to or after radiofrequency field (RFF) exposure. The X-ray energy and tube current were $130 \mathrm{kV}$ and $23 \mathrm{~mA}$, respectively. Sham-irradiated cultures ( $0 \mathrm{~Gy})$ were left on the turntable of the running Precision X-ray irradiator for 2 min with the X-ray source turned off and were used as controls.

For RFF exposure, a PERL $\mathrm{M}^{+}$oscillator amplifier (Resonant Light Technology Inc., Courtenay, Canada; Serial \# PM 171116) was used to produce 27.125-MHz fields, square-wave amplitude-modulated at 100 or $1000 \mathrm{~Hz}$, with a peak-to-peak amplitude of 
$5 \mathrm{~V}$. The modulating frequencies were generated using a ProGen II frequency generator with an output impedance of $50 \Omega$ and a duty cycle of $50 \%$ (Resonant Light Technology, Courtenay, Canada; Serial \#: PG 171211) with square and sinusoidal wave options. The resulting radiofrequencies were then broadcast through an argon-filled plasma ray tube with leaded glass electrodes [length: $29 \mathrm{~cm}$, diameter: $2.55 \mathrm{~cm}$, pressure: 20 Torr $(100 \%$ argon)], acting as an antenna, onto the cells. For sham-RFF exposure (no radiofrequency field), unirradiated ( 0 Gy) cell cultures were placed under the plasma ray tube when turned off. The setup is shown in Fig. 1A. A maximum of 16 cell culture flasks, stacked
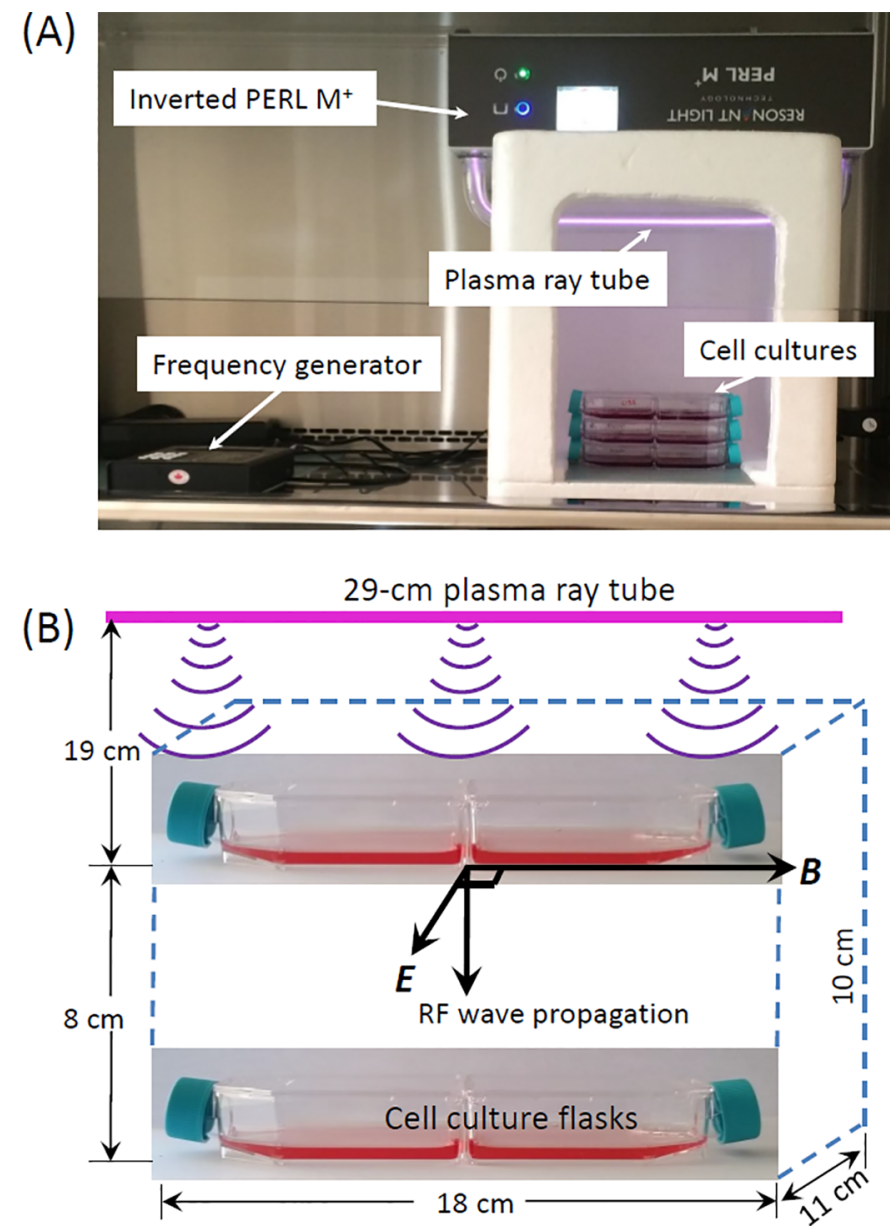

FIG. 1: (A) Photograph of the electromagnetic field (EMF) exposure system, with the PERL $\mathrm{M}^{+}$inverted on an appropriately cut Styrofoam box. (B) A two-dimensional schematic diagram showing the top and bottom cell culture planes of the $2 \times 2 \times 4$ flask matrix. In the setup, the plasma ray tube is centered horizontally above the cell culture flasks, such that the induced magnetic field $(B)$ is parallel to the base of the flask and the induced electric field $(E)$ in the culture medium is parallel to the width of the flask.

Volume 10, Issue 1, 2020 
in groups of four, could be exposed at a given time. As illustrated in Fig. 1B, the volume occupied by the cell culture layers had outside dimensions of $11 \mathrm{~cm}$ (Width: two flasks breadthwise) $\times 18 \mathrm{~cm}$ (Length: two flasks lengthwise) $\times 10 \mathrm{~cm}$ (Height: four flasks by height). The perpendicular distances from the axis of the plasma tube to the four cell culture planes were 19.0, 21.4, 23.8, and $27.0 \mathrm{~cm}$. Each cell layer was covered with 10 $\mathrm{ml}$ of culture medium (medium depth: $3.5 \mathrm{~mm}$ ).

The induced electric fields in the cell cultures were estimated using a large-loop H-field probe (Beehive Electronics, Sebastopol, California, USA; cat \# 100C) coupled to a digital storage oscilloscope (Hantek Electronic Co. Ltd., Qingdao, China; Serial \# DSO5062BM). For this, the loop was positioned perpendicularly (in air) to the RF wave (Fig. 1B), at the respective cell culture planes. During sham exposure (background with the plasma tube turned off), the mean electric field was found to be $3.7 \mathrm{~V} / \mathrm{m}$, and was subtracted from subsequently measured peak fields when the tube was turned on. The induced peak electric fields $\left(E_{\text {peak }}\right)$ were measured in triplicate for each modulated frequency and perpendicular distance from the plasma ray tube. No significant frequencydependent variation in the induced electric fields was observed, and the mean of all measurements at each plane was taken as the peak electric field at that location.

The mean induced peak electric fields along the bottom of the partially filled rectangular tissue culture flasks (background subtracted) were then used to estimate the peak magnetic flux density $\left(B\right.$, in T) from $E_{\text {peak }}=2 h \pi f B$, derived using Faraday's Law, ${ }^{12}$ where $f$ is the transmitted frequency $\left(27.125 \times 10^{6} \mathrm{~Hz}\right)$, and $2 h$ is the depth of the cell culture medium $(0.0035 \mathrm{~m})$. The uniformity of the electric field is dependent on the ratio of the depth to the width $(0.05 \mathrm{~m})$ of the culture medium, and diminishes as the volume (and depth) of the medium increases. Here, the ratio is less than 0.3 and the peak electric fields can be estimated to within an uncertainty of $\leq 1 \% .^{12}$ The induced current densities $(J)$ were also estimated from the peak electric fields, according to the relation $J=\sigma E$, assuming a conductivity $(\sigma)$ of $1.5 \mathrm{~S} / \mathrm{m}$ for the cell culture medium. ${ }^{12}$ The estimated induced peak electric fields, magnetic flux density, and current density are presented in Table 1.

\section{Clonogenic Survival}

After treatment, the cell cultures were incubated at $37^{\circ} \mathrm{C}$ in a humidified atmosphere $(95 \%$ air, 5\% $\mathrm{CO}_{2}$ ) for 10 days (for DU145, Be11, and L132) and 15 days (for MeWo) for colony

TABLE 1: Estimated peak electric field $(E)$, magnetic flux density $(B)$, and current density $(J)$ induced at a distance $(d)$ from the axis of a 29 -cm plasma ray tube

\begin{tabular}{|c|c|c|c|}
\hline $\boldsymbol{d}(\mathbf{c m})$ & $\boldsymbol{E}(\mathbf{V} / \mathbf{m})$ & $\boldsymbol{B}(\boldsymbol{\mu} \mathbf{T})$ & $\boldsymbol{J}\left(\mathbf{A} / \mathbf{m}^{2}\right)$ \\
\hline 19.0 & $6.69 \pm 1.15$ & 22.43 & 10.04 \\
\hline 21.4 & $5.25 \pm 0.69$ & 17.60 & 7.88 \\
\hline 23.8 & $3.24 \pm 1.11$ & 10.86 & 4.86 \\
\hline 27.0 & $2.01 \pm 0.51$ & 6.74 & 3.02 \\
\hline
\end{tabular}


formation. The cultures were terminated by decanting the growth media, washing the colonies with phosphate buffered saline, and fixing them in glacial acetic acid:methanol:water $(1: 1: 8, \mathrm{v} / \mathrm{v} / \mathrm{v})$. Colonies were then stained in $0.01 \%$ amido black in fixative, washed in tap water, air-dried, and counted using a stereoscopic microscope (Nikon, Japan; Model \# SMZ-1B). Three independent experiments were performed for each cell line and the mean surviving fractions were determined for each cell line. The modulatory effect of radiofrequency fields on radiosensitivity was expressed as a survival modifying factor $\left(M F_{\text {survival }}\right)$, given as the ratio of surviving fractions at 2 Gy in the absence and presence of RFF:

$$
M F_{\text {survival }}=\frac{S F(2 G y)}{S F(R F F+2 G y)} \text { or } \frac{S F(2 G y)}{S F(2 G y+R F F)}
$$

The criteria for inhibition, no effect, and enhancement of radiosensitivity by RFF are $M F_{\text {survival }}<1.0, M F_{\text {survival }}=1.0$, and $M F_{\text {survival }}>1.0$, respectively. RFF +2 Gy and 2 Gy + RFF denote radiofrequency exposure before and after X-ray irradiation, respectively.

\section{Assessment of DNA Damage Response}

To evaluate the role of RFF exposure in radiation-induced DNA damage response, the micronucleus formation assay was used. ${ }^{13}$ For this, exponentially growing cells were trypsinized into single-cell suspensions and seeded (40,000 cells per plate) into $35-\mathrm{mm}$ plastic petri dishes containing 22-mm glass cover slips, to a final medium volume of $2 \mathrm{~mL}$, and incubated at $37^{\circ} \mathrm{C}$ in a humidified atmosphere $\left(95 \%\right.$ air, $\left.5 \% \mathrm{CO}_{2}\right)$ for $2 \mathrm{~h}$. The cells were exposed to $100-$ or $1000-\mathrm{Hz}$ amplitude-modulated radiofrequency fields and $\mathrm{X}$-rays ( 0 or $2 \mathrm{~Gy}$ ) as described in Section B. Immediately after exposure, and not later than $30 \mathrm{~min}$, the cultures were treated with cytochalasin-B dissolved in DMSO to a final concentration of $2 \mu \mathrm{g} / \mathrm{mL}$ and incubated.

In a preliminary micronucleus experiment, using the lung fibroblasts (L132), it was observed that a typical 40-h incubation yielded a large proportion of multinucleated cells. ${ }^{13}$ As the micronucleus assay requires that micronuclei be scored in only binucleated cells, it was necessary to determine the doubling times of all cell lines to guide the timing of subsequent experiments. The doubling times for the L132, MeWo, Be11, and DU145 cell lines were found to be $21,47,28$, and $30 \mathrm{~h}$, respectively. Therefore, the cell cultures were correspondingly terminated after being incubated for 24, 48, 42, and 42 $\mathrm{h}$, respectively. For this, the samples were fixed with a methanol:acetic acid mixture $(3: 1, v / v)$, air-dried, and stained with acridine orange, and the cover slips mounted on glass microscope slides for fluorescence microscopy. Micronuclei in binucleated cells were counted, using a fluorescence microscope (LABOPHOT-2, Nikon, Japan; serial \# 465393). At least 500 binucleated cells were evaluated per experiment. Micronucleus frequency (MNF) was expressed as the mean number of micronuclei per binucleated cell. The proportion of binucleated cells and the nucleation index, BNI (proportion of cells with two main nuclei), were determined as indicators of cell proliferation. 
A micronucleus-frequency-based RFF treatment related modifying factor was derived as follows: $M F_{\mathrm{MNF}}=\left(\mathrm{MNF}_{2 \mathrm{~Gy}}-\mathrm{MNF}_{\text {medium }}\right) /\left(\mathrm{MNF}_{2 \mathrm{~Gy}+\mathrm{RFF}}-\mathrm{MNF}_{\mathrm{RFF}}\right)$ or $\left(\mathrm{MNF}_{2 \mathrm{~Gy}}-\right.$ $\left.\mathrm{MNF}_{\text {medium }}\right) /\left(\mathrm{MNF}_{\mathrm{RFF}+2 \mathrm{~Gy}}-\mathrm{MNF}_{\mathrm{RFF}}\right)$, where $\mathrm{MNF}_{\text {medium }}$ and $\mathrm{MNF}_{\mathrm{RFF}}$ are the micronucleus frequencies of the growth medium and RFF controls, respectively. The subscripts RFF +2 Gy and 2 Gy + RFF denote radiofrequency exposure before and after X-ray irradiation, respectively. The corresponding modifying factor, based on binucleation, was given as $M F_{\mathrm{BNI}}=\left(\mathrm{BNI}_{2 \mathrm{~Gy}} / \mathrm{BNI}_{\text {medium }}\right) /\left(\mathrm{BNI}_{2 \mathrm{~Gy}+\mathrm{RFF}} / \mathrm{BNI}_{\mathrm{RFF}}\right)$ or $\left(\mathrm{BNI}_{2 \mathrm{~Gy}} / \mathrm{BNI}_{\text {medium }}\right) /\left(\mathrm{BNI}_{\mathrm{RFF}}\right.$ $\left.+2 \mathrm{~Gy} / \mathrm{BNI}_{\mathrm{RFF}}\right)$. A modifying factor of $>1$, 1 , or $<1$ indicates a reduction, no effect, or an enhancement in MNF or BNI in irradiated cells by RFF, respectively.

\section{E. Statistical Analysis}

Data analyses were performed with GraphPad Prism software (San Diego, CA, USA). All data were presented as the mean $( \pm$ SEM) from three independent experiments. Where applicable, errors were determined using appropriate error propagation formulae. For associations, linear regression analyses were used.

\section{RESULTS}

\section{A. Effect of Radiofrequency Fields on Radiosensitivity}

The modulatory effect of the radiofrequency fields on radiosensitivity was expressed as a modifying factor $(M F)$, given as the ratio of surviving fractions at 2 Gy in the absence and presence of RFF. The modifying factors for the four cell lines are presented in Table 2. Modifying factors of $<1.0,1.0$, and $>1.0$ indicate inhibition, no effect, and enhancement of radiosensitivity by RFF, respectively.

\section{B. Effect of Radiofrequency Fields on Radiation-Induced Micronucleus Frequency}

The cytokinesis-block micronucleus assay was used to determine if radiofrequency fields had an effect on radiation-induced DNA damage and block of cell proliferation.

TABLE 2: Modifying factors $(M F)$, relative to the surviving fraction at 2 Gy of X-ray treatment alone, for the DU145, MeWo, Be11, and L132 cell lines when cells were treated with combinations of 100- and 1000-Hz modulated radiofrequency fields and 2 Gy of X-rays. Errors were calculated using error propagation formulae for ratios

\begin{tabular}{|l|c|c|c|c|}
\hline \multicolumn{1}{|c|}{ Treatment } & DU145 & MeWo & Be11 & L132 \\
\hline $100 \mathrm{~Hz}+2 \mathrm{~Gy}$ & $1.01 \pm 0.06$ & $1.10 \pm 0.30$ & $1.86 \pm 0.25$ & $1.20 \pm 0.13$ \\
\hline $2 \mathrm{~Gy}+100 \mathrm{~Hz}$ & $1.15 \pm 0.05$ & $1.16 \pm 0.33$ & $1.63 \pm 0.46$ & $1.47 \pm 0.30$ \\
\hline $1000 \mathrm{~Hz}+2 \mathrm{~Gy}$ & $0.99 \pm 0.15$ & $1.43 \pm 0.20$ & $2.58 \pm 0.44$ & $2.28 \pm 0.40$ \\
\hline $2 \mathrm{~Gy}+1000 \mathrm{~Hz}$ & $1.02 \pm 0.14$ & $1.54 \pm 0.18$ & $2.48 \pm 0.33$ & $2.64 \pm 0.51$ \\
\hline
\end{tabular}


For this, treatment-induced changes in micronucleus yield and binucleation were assessed. The data presented in Fig. 2 show that exposure of the prostate cancer cell line, DU145, to the 100- and $1000-\mathrm{Hz}$ modulated radiofrequency fields does not result in a significant change in background (medium control) micronucleus yield. Exposure of cells to the $100-\mathrm{Hz}$ modulated RFF prior to or after 2 Gy of X-rays did not affect micronucleus yield (Fig. 2A). While pre-exposure of cells to the $1000-\mathrm{Hz}$ modulated RFF did not affect radiation-induced micronucleus frequency, RFF exposure after irradiation resulted in an $\sim 18 \%$ reduction in DNA damage (Fig. $2 \mathrm{~B}$ ).

The binucleation indices in the DU145 cells for the various treatments are also presented in Fig. 2. For the 100-Hz modulated RFF, no marked changes were observed in cellular capacity to go through a cell division (Fig. 2C). Also, a 2-Gy dose of X-rays or a 1000-Hz modulated RFF treatment did not affect binucleation (Fig. 2D). However, when this RFF field was combined with 2 Gy of X-rays, a reduction in cell proliferation of more than $30 \%$ was found.
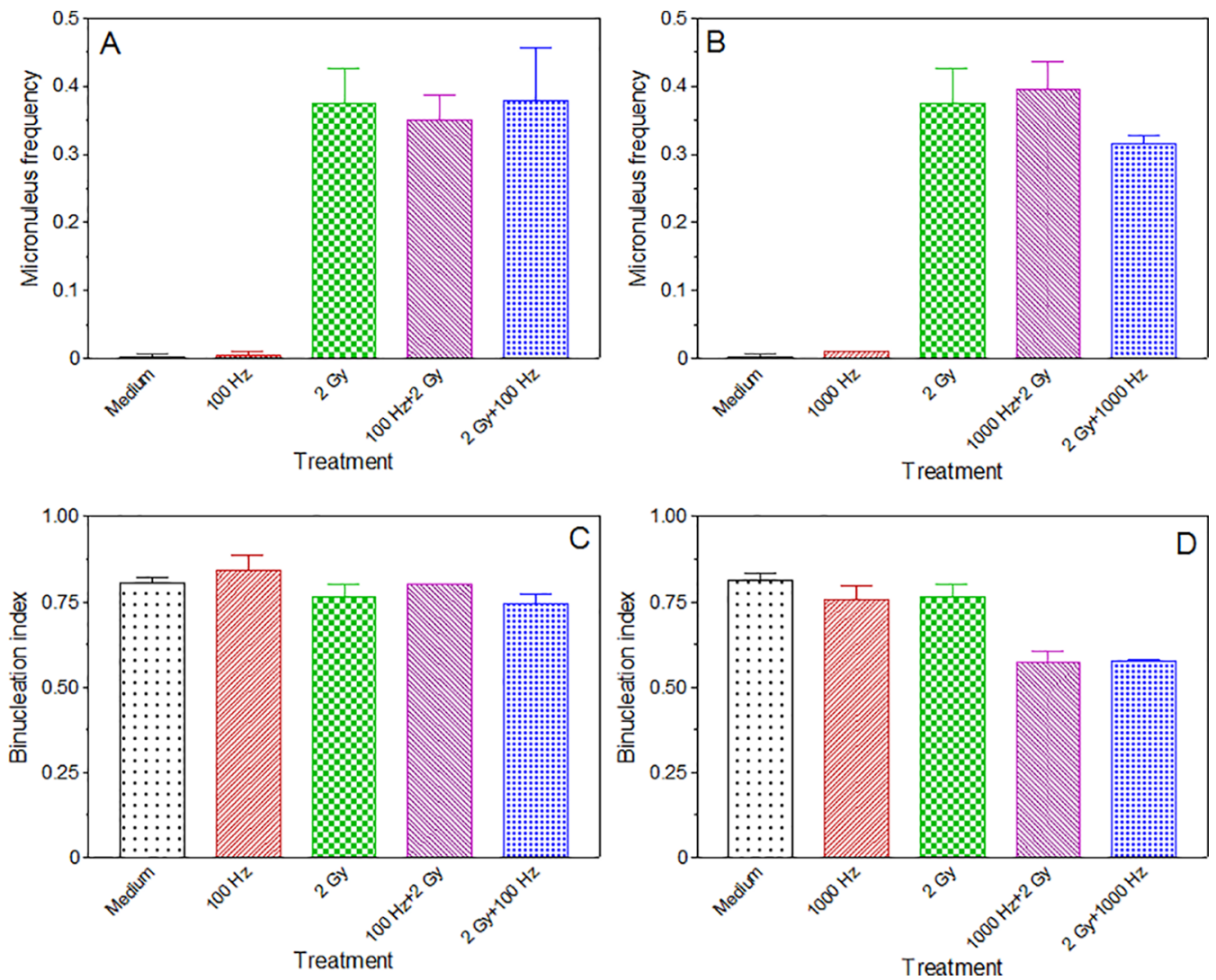

FIG. 2: Micronucleus yield (A and B) and binucleation index (C and D) in the prostate cancer cell line, DU145, after treatment with 2 Gy of X-rays alone or in combination with 100- and 1000-Hz modulated radiofrequency fields 
Exposure of MeWo cells to both $100-$ and $1000-\mathrm{Hz}$ modulated RFF resulted in an $\sim 1.8$-fold increase in micronucleus yield over background (Fig. 3). Combined treatment with 2 Gy of X-rays and the $100-\mathrm{Hz}$ modulated RFF led to an $\sim 1.2$-fold increase in micronucleus yield, regardless of treatment sequence (Fig. 3A). When the 1000-Hz modulated RFF was combined with 2 Gy of X-rays, a twofold increase in DNA damage emerged (Fig. 3B).

Figure 3C shows no effect on the binucleation index when MeWo cells were exposed to X-rays or the $100-\mathrm{Hz}$ modulated RFF alone. An approximately $18 \%$ reduction in binucleation was obtained from the combination treatments. While a 2-Gy dose of $\mathrm{X}$-ray treatment alone or combined treatment with the $1000-\mathrm{Hz}$ modulated RFF resulted in an expected decline in binucleation, exposure to the RFF alone increased cell proliferation by more than $10 \%$ (Fig. 3D).

Exposure of Be11 cells to the 100- and 1000-Hz modulated RFF resulted in $~ 2.0$ and $\sim 4.0$-fold increases in micronucleus yield compared to background, respectively (Fig. 4). Combination treatment with the $100-\mathrm{Hz}$ modulated RFF prior to or after 2 Gy of X-rays led to an $\sim 24 \%$ and $\sim 30 \%$ reduction in micronucleus yield, respectively (Fig.
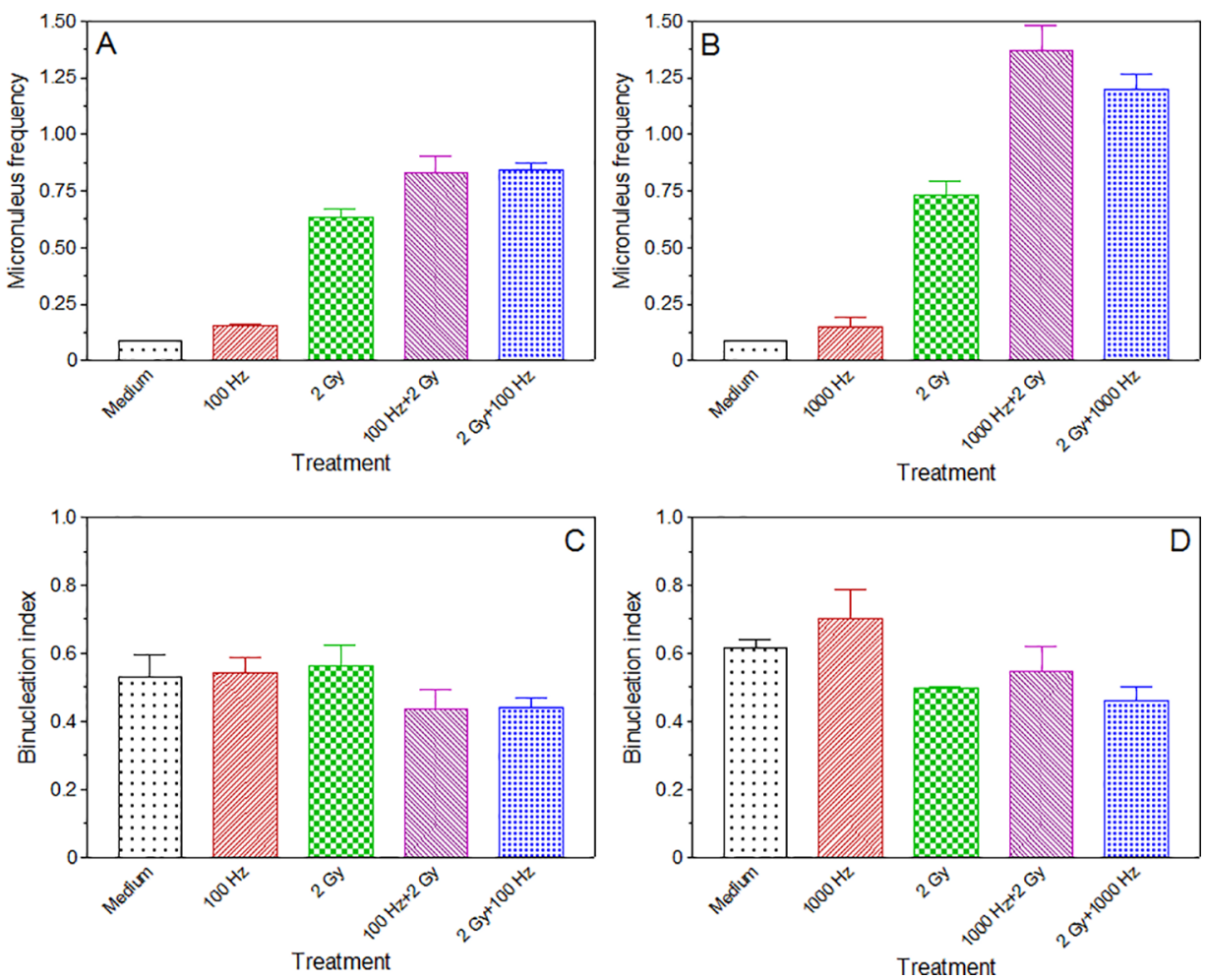

FIG. 3: Micronucleus yield (A and B) and binucleation index (C and D) in the melanoma cell line, MeWo, after treatment with 2 Gy of X-rays alone or in combination with $100-$ and $1000-\mathrm{Hz}$ modulated radiofrequency fields 

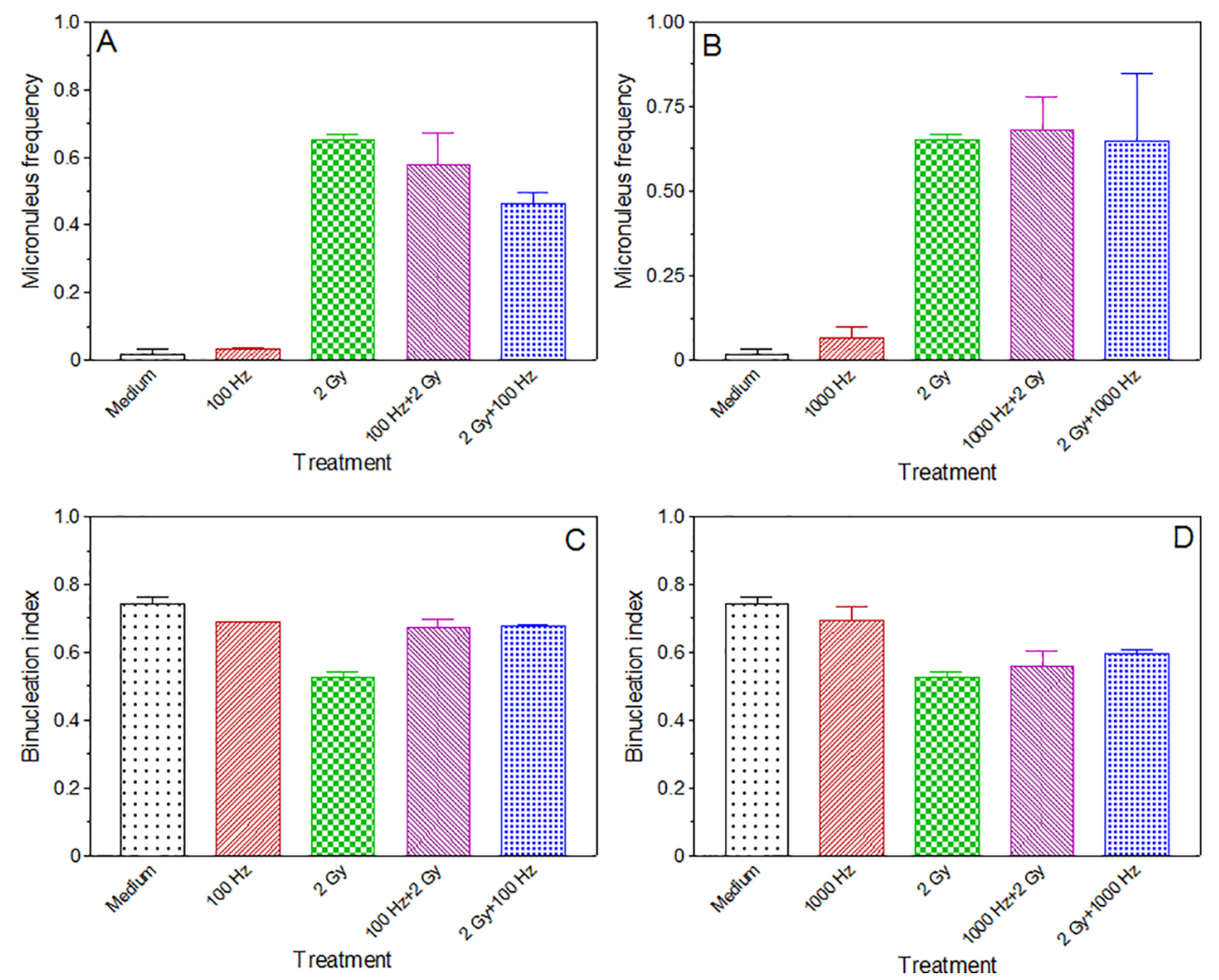

FIG. 4: Micronucleus yield (A and B) and binucleation index (C and D) in the melanoma cell line, Be11, after treatment with 2 Gy of X-rays alone or in combination with $100-$ and $1000-\mathrm{Hz}$ modulated radiofrequency fields

4A). On the other hand, the $1000-\mathrm{Hz}$ modulated RFF had no effect on radiation-induced micronucleus frequency (Fig. 4B).

A slight reduction in binucleation was seen when cells were exposed to the 100or $1000-\mathrm{Hz}$ modulated RFF alone (Fig. 4). The decrease in binucleation at 2 Gy was reversed to levels close to those in background (medium and RFF control), when cells were concomitantly treated with the 100-Hz modulated RFF (Fig. 4C). A similar, but less pronounced, recovery in binucleation was observed when cells were treated with a combination of X-rays and the 1000-Hz modulated RFF (Fig. 4D).

For the normal lung fibroblasts, L132, exposure to $100-\mathrm{Hz}$ modulated RFF alone increased micronucleus yield, relative to background (Fig. 5A). Combined treatment with this field led to up to a 1.8-fold increase in micronucleus yield at $2 \mathrm{~Gy}$, with the RFF exposure after X-ray irradiation being more damaging. Treatment with the $1000-\mathrm{Hz}$ modulated RFF alone had no impact on the background level of micronuclei (Fig. 5B). As in the case of the $100-\mathrm{Hz}$ modulated RFF, combination treatment with the $1000-\mathrm{Hz}$ modulated RFF resulted in an up to 3.3-fold increase in micronucleus yield, with RFF exposure after 2 Gy of X-rays being more potent (Fig. 5B). 

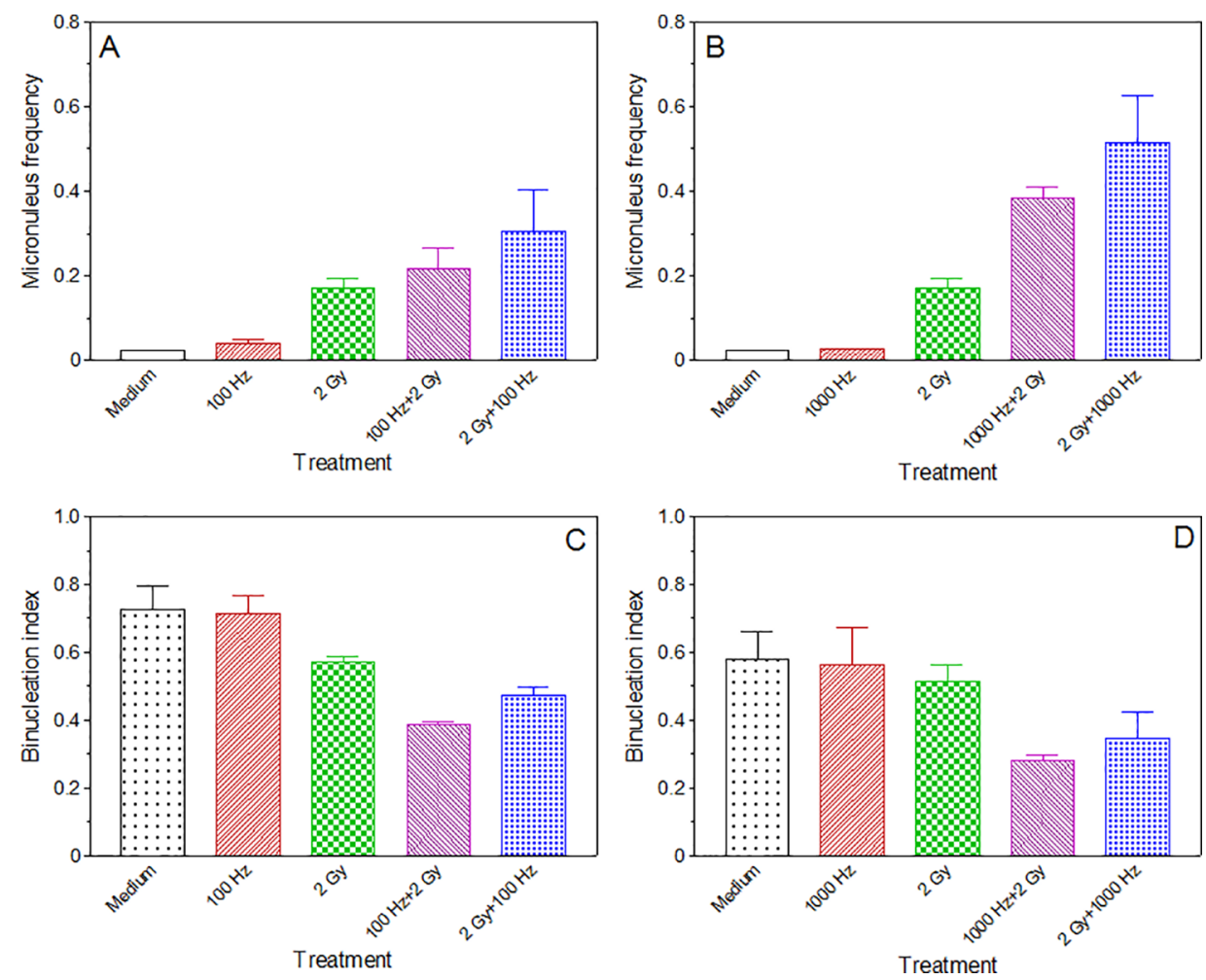

FIG. 5: Micronucleus yield (A and B) and binucleation index (C and D) in the normal lung fibroblasts, L132, after treatment with 2 Gy of X-rays alone or in combination with $100-$ and $1000-\mathrm{Hz}$ modulated radiofrequency fields

Data for binucleation in the L132 cell line are presented in Figs. 5(C) and 5(D). No effect on binucleation is apparent when cells were exposed to either the 100- or 1000$\mathrm{Hz}$ modulated RFF alone. Combined treatment with these radiofrequency fields reduced binucleation, relative to that obtained for the 2 Gy only treatment, with RFF exposure after X-ray irradiation being less potent in arresting cell proliferation.

Treatment-induced modifying factors based on micronucleus yield, as described in Section D, are presented in Table 3. In the DU145 and Be11 cell lines, combining radiofrequency fields with $\mathrm{X}$-ray irradiation either had no effect $(M F \approx 1.0)$ or resulted in small reductions $(M F>1.0)$ in micronucleus yield. Similar treatment of the MeWo and L132 cell lines led to an $\sim 1.14$ - to 3.33-fold enhancement $(M F<1.0)$ in micronucleus frequency.

\section{Relationship between Radiosensitivity and Micronucleus Yield}

To assess whether the radiosensitivity modifying effects seen when cells were concomitantly treated with radiofrequency fields and X-rays are influenced by changes in the level of DNA damage, the modifying factors derived from micronucleus yield (Table 3 ) 
TABLE 3: Modifying factors $(M F)$, relative to X-ray treatment alone, derived from the micronucleus frequency presented in Figs. 2, 3, 4, and 5 for the DU145, MeWo, Be11, and L132 cell lines, respectively, as described in Section D. Errors were calculated using error propagation formulae for ratios

\begin{tabular}{|l|c|c|c|c|}
\hline \multicolumn{1}{|c|}{ Treatment } & DU145 & MeWo & Be11 & L132 \\
\hline $100 \mathrm{~Hz}+2 \mathrm{~Gy}$ & $1.07 \pm 0.19$ & $0.88 \pm 0.11$ & $1.16 \pm 0.23$ & $0.83 \pm 0.26$ \\
\hline $2 \mathrm{~Gy}+100 \mathrm{~Hz}$ & $0.99 \pm 0.25$ & $0.79 \pm 0.11$ & $1.47 \pm 0.19$ & $0.55 \pm 0.22$ \\
\hline $1000 \mathrm{~Hz}+2 \mathrm{~Gy}$ & $0.96 \pm 0.16$ & $0.53 \pm 0.07$ & $1.03 \pm 0.18$ & $0.41 \pm 0.07$ \\
\hline $2 \mathrm{~Gy}+1000 \mathrm{~Hz}$ & $1.21 \pm 0.17$ & $0.62 \pm 0.08$ & $1.10 \pm 0.40$ & $0.30 \pm 0.08$ \\
\hline
\end{tabular}

were plotted against those determined from clonogenic cell survival (Table 2). Figure $6 \mathrm{~A}$ shows a weak trend $\left[\mathrm{Y}=(0.36 \pm 0.35) \mathrm{X}+(0.49 \pm 0.47) ; R^{2}=0.1532 ; P=0.3376\right]$ (dashed line) where cell lines that are more radiosensitized produce lower yields of micronuclei, following combined treatment with the $100-\mathrm{Hz}$ modulated RFF. Exclusion of the Be11 cell line which seems to be an outlier yields a strong correlation $[\mathrm{Y}=(-1.08 \pm$ $0.22) \mathrm{X}+(2.12 \pm 0.25) ; R^{2}=0.8597 ; P=0.0078$; Fig. $6 \mathrm{~A}$; solid line] between the RFFinduced radiosensitization and DNA damage, whereby highly radiosensitized cell lines tend to express elevated levels $(M F<1.0)$ of micronuclei frequency.

A similarly weak correlation $\left[\mathrm{Y}=(-0.15 \pm 0.19) \mathrm{X}+(1.05 \pm 0.38) ; R^{2}=0.0903 ; P=\right.$ $0.4695]$ was found for radiosensitization and micronucleus yield for the combined treatment with the $1000-\mathrm{Hz}$ modulated RFF, with more radiosensitized cell lines expressing higher levels of micronuclei (Fig. 6B; dashed line). Again, exclusion of the Be11 cell
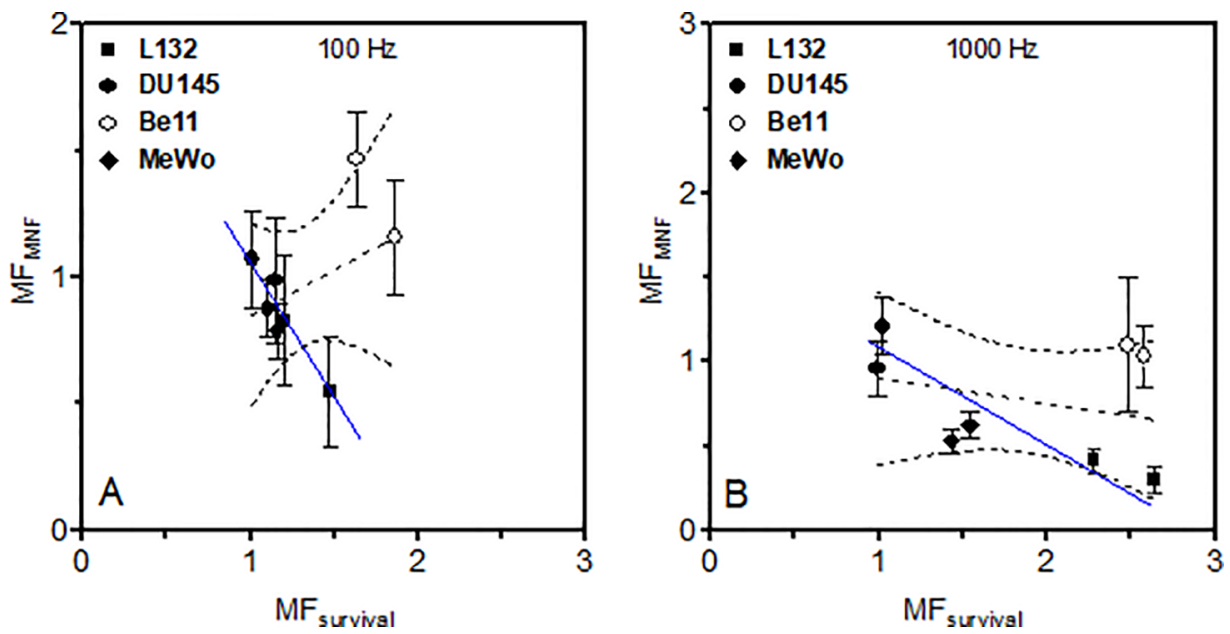

FIG. 6: Plot of modifying factors from micronucleus frequency (MNF) at 2 Gy as a function of modifying factors from surviving fractions at 2 Gy for four cell lines: (A) combined treatment with 100-Hz modulated RFF and (B) combined treatment with 1000-Hz modulated RFF. Dashed curves represent the $95 \%$ confidence interval 
TABLE 4: Modifying factors $(M F)$, relative to X-ray treatment alone, derived from the binucleation indices presented in Figs. 2, 3, 4, and 5 for the DU145, MeWo, Be11, and L132 cell lines, respectively, as described in Section D. Errors were calculated using error propagation formulae for ratios

\begin{tabular}{|l|c|c|c|c|}
\hline \multicolumn{1}{|c|}{ Treatment } & DU145 & MeWo & Be11 & L132 \\
\hline $100 \mathrm{~Hz}+2 \mathrm{~Gy}$ & $0.91 \pm 0.07$ & $1.32 \pm 0.28$ & $0.73 \pm 0.04$ & $1.46 \pm 0.18$ \\
\hline $2 \mathrm{~Gy}+100 \mathrm{~Hz}$ & $0.84 \pm 0.06$ & $1.32 \pm 0.24$ & $0.72 \pm 0.04$ & $1.20 \pm 0.16$ \\
\hline $1000 \mathrm{~Hz}+2 \mathrm{~Gy}$ & $0.80 \pm 0.08$ & $1.04 \pm 0.19$ & $0.88 \pm 0.09$ & $1.78 \pm 0.48$ \\
\hline $2 \mathrm{~Gy}+1000 \mathrm{~Hz}$ & $0.81 \pm 0.06$ & $1.23 \pm 0.19$ & $0.76 \pm 0.07$ & $1.45 \pm 0.49$ \\
\hline
\end{tabular}

line strengthens this correlation $\left[\mathrm{Y}=(-0.45 \pm 0.13) \mathrm{X}+(1.42 \pm 0.22) ; R^{2}=0.7691 ; P=\right.$ 0.0218; Fig. 6B; solid line].

As described in Section $\mathrm{C}$, the modifying factors derived from binucleation indices are presented in Table 4. A combined treatment of the MeWo and L132 cell lines with radiofrequency fields and X-ray irradiation either had no effect $(M F \approx 1.0)$ or resulted in small reductions $(M F>1.0)$ in binucleation. Similar treatment of the DU145 and Be11 cell lines resulted in an $\sim 1.1$ - to 1.4 -fold enhancement $(M F<1.0)$ in cell proliferation.

\section{Relationship between Radiosensitivity and Binucleation}

The role of cell proliferation in the modulation of radiosensitivity by radiofrequency fields was assessed by plotting modifying factors derived from binucleation indices (Table 4) against those derived from clonogenic cell survival (Table 2). Figure 7A demonstrates a weak trend $\left[\mathrm{Y}=(-0.52 \pm 0.34) \mathrm{X}+(1.75 \pm 0.46) ; R^{2}=0.2786 ; P=0.1788\right]$ where an increase in radiosensitization is mirrored by enhanced $(M F<1.0)$ binucleation, after combined treatment with the $100-\mathrm{Hz}$ modulated RFF. A similarly weak, but reversed trend $[\mathrm{Y}=(0.20 \pm 0.20) \mathrm{X}+(0.72 \pm$ $\left.0.39) ; R^{2}=0.1421 ; P=0.3573\right]$ emerged for the $1000-\mathrm{Hz}$ modulated RFF combined treatment (Fig. 7B; dashed line). However, as in the case of micronucleus yield, exclusion of the Be11 cell line strengthens the correlation $\left[\mathrm{Y}=(0.51 \pm 0.13) \mathrm{X}+(0.35 \pm 0.23) ; R^{2}=0.7976 ; P=\right.$ 0.0165 ; Fig. 7B; solid line] between the RFF-induced radiosensitization and cell proliferation, where more radiosensitized cell lines tend to have reduced $(M F>1.0)$ binucleation.

\section{DISCUSSION}

\section{A. Effect of Radiofrequency Fields on Radiation-Induced Micronucleus Frequency, and the Possible Impact on Cell Survival}

Reports on the capacity of radiofrequency fields at inducing micronuclei are mixed. While some studies do not demonstrate elevated levels of micronuclei in cellular systems following RFF exposure, ${ }^{14-16}$ others have shown enhanced micronucleus formation. ${ }^{17,18}$ The slight elevation in micronucleus formation seen in this study may be due to the much lower frequencies used. 

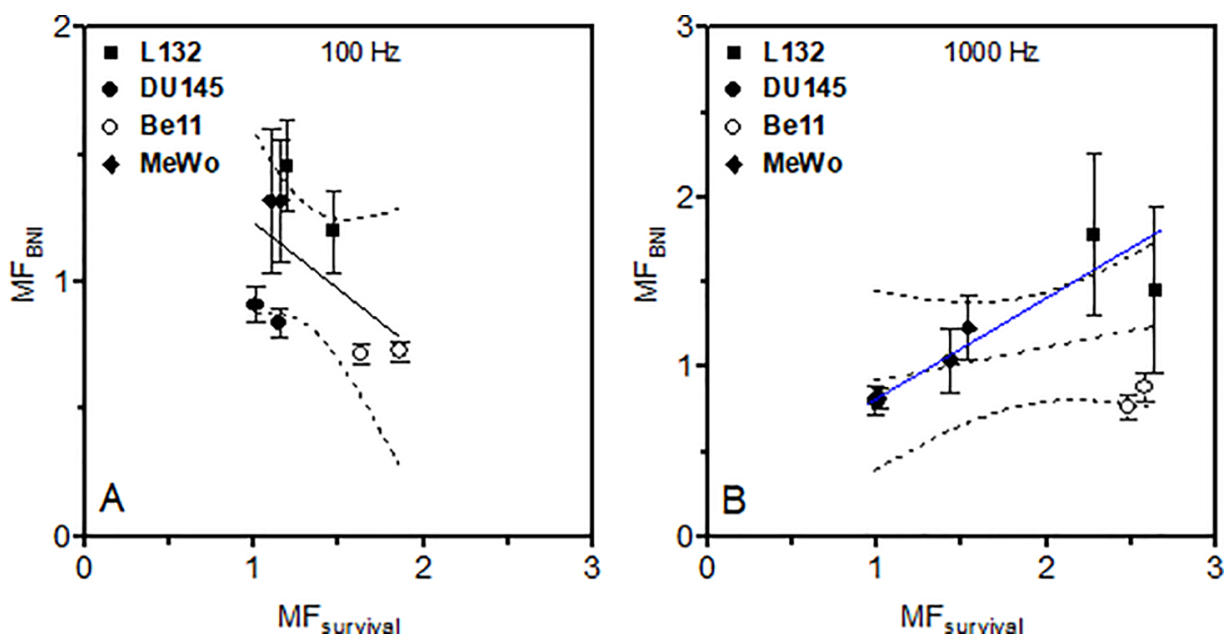

FIG. 7: Plot of modifying factors from binucleation index (BNI) at 2 Gy of X-rays as a function of modifying factors from surviving fractions at $2 \mathrm{~Gy}$ for four cell lines: (A) combined treatment with $100-\mathrm{Hz}$ modulated RFF and (B) combined treatment with 1000-Hz modulated RFF. Dashed curves represent the $95 \%$ confidence interval

From the summary of the micronucleus data presented in Fig. 6, the melanoma cell line (Be11) is a clear outlier, being highly radiosensitized but exhibiting reduced levels of micronuclei $\left(M F_{\mathrm{MNF}}>1.0\right)$. Low micronucleus yield can be attributed to the combination treatment causing such extensive damage to the cells that they die and, therefore, do not present as binucleated cells with micronuclei for assessment. ${ }^{13}$ The number of lethal lesions at $2 \mathrm{~Gy}$ is given as the negative natural logarithm of $S F_{2} \cdot{ }^{13,19,20}$ The ability of a cell to survive a certain level of micronucleus yield can be expressed in terms of the number of micronuclei per lethal lesion (i.e., the number of micronuclei that would constitute a lethal event in the cell). ${ }^{13}$ Here, the combination treatments resulted in $0.35-0.52$ micronuclei per lethal lesion in the Be11 cell line, implying that these cells are more resistant to micronuclei-mediated death than the L132 cells (0.17-0.40 micronuclei per lethal lesion). For the DU145 and MeWo cells, the number of micronuclei per lethal lesion ranged from 0.80 to 1.00 and 0.69 to 1.14 , respectively, indicating an even higher resistance to micronucleus lethality. Treatment-induced reduction in micronucleus yield is, therefore, not due to cell death.

A reduced micronucleus yield can also be a consequence of efficient DNA repair, as this would lead to fewer residual acentric fragments to present as micronuclei. In fact, Be11 cells have been shown to exhibit 97\% DNA double-strand break rejoining, 20 $\mathrm{h}$ after $\gamma$-ray irradiation. ${ }^{21,22}$ Elsewhere, the L132 cells, which also show low numbers of micronuclei per lethal lesion but an RFF-induced increase in micronucleus yield, have been found to be equally repair proficient. ${ }^{23}$ However, the DU145 and MeWo cells which fall between the Be11 and L132 cells in terms of micronucleus yield are intrinsically less efficient in DNA double-strand break rejoining at $\sim 88 \%{ }^{24}$ and $\sim 81 \%$, ${ }^{21}$ respectively. Exclusion of the Be11 cell line yields a strong frequency-independent 
correlation between RFF-mediated micronucleus yield and radiosensitization, with the more radiosensitized cell lines showing increased micronucleus yield (Fig. 6). The relationship between radiofrequency-mediated changes in micronucleus yield and DNA repair is, thus, not straightforward. However, these findings seem to suggest that radiofrequency exposure perturbs DNA damage repair processes, a phenomenon that could have important implications in radiotherapy and radiation protection.

\section{B. Effect of Radiofrequency Fields on Radiation-Induced Changes in Binucleation}

The binucleation index can be used as an indicator of cell proliferation. ${ }^{25-27} \mathrm{~A}$ high binucleation index indicates a large proportion of cells progressing through a cell division, and vice versa. The impact of radiofrequency exposure on cell proliferation and cell cycle progression is not consistent. Although some studies have demonstrated changes in cell cycle progression and reductions in cell proliferation after extended exposure to RFF, ${ }^{28,29}$ others have failed to detect similar effects. ${ }^{30-32}$ Based on the binucleation data presented here, RFF exposure does not appear to have an impact on proliferation of DU145, MeWo, Be11, and L132 cells. The data presented in Fig. 7 again show the Be11 cell line as a possible outlier, which is highly radiosensitized but retains a high level of cell division $\left(M F_{\mathrm{BNI}}<1.0\right)$. Elevated radiosensitivity in cells that continue to progress through a division after treatment may be related to an absence of a cell cycle block that might be required for adequate recovery. However, this cell line exhibits both $G_{1}$ - and $\mathrm{G}_{2}$-phase blocks at 12 and $16 \mathrm{~h}$, respectively, while its 53 mutated counterpart (MeWo) shows only a G2-phase block at about $18 \mathrm{~h} .{ }^{33}$ Therefore, the elevated binucleation in Be11 cannot be explained by the inexistence of a cell cycle arrest. The increased radiosensitivity in Be11 can be attributed to the existence of the $\mathrm{G}_{1}$-phase block as arrests at this stage of the cell cycle are said to be responsible for high radiosensitivity. ${ }^{34}$

Considering only the DU145, MeWo, and L132 cell lines, cells that showed reduced binucleation $\left(M F_{\mathrm{BNI}}>1.0\right)$ tended to be more radiosensitized. This may be due to the fact that cell cycle arrests in these cell lines after $\sim 7$ Gy irradiation have been noted to last as long as $40 \mathrm{~h}^{23,33}$ It should be noted that except for the MeWo cell line (48 h), the micronucleus assay was terminated after $24-42 \mathrm{~h}$, based on predetermined doubling times (Section D). It is, therefore, likely that the binucleation indices reported here represent levels that correspond to incomplete re-entry of cells into cycling. Nonetheless, these experiments were performed at $2 \mathrm{~Gy}$ and the residence time of cells in phase blocks can be expected to be much shorter, as demonstrated by Su and Little almost three decades ago. ${ }^{35}$ The finding that radiofrequencies may activate proliferation in certain cell types could be of significance to wound healing and needs to be further interrogated.

\section{CONCLUSIONS}

The data presented here suggest that, on average, cell lines that are more radiosensitized by radiofrequency field exposure show elevated levels of micronucleus yield. 
This phenomenon appears to be RFF frequency independent. Furthermore, an increase in proliferative index correlates with a high level of radiosensitization by the $100-\mathrm{Hz}$ modulated field and minimal radiosensitization by the $1000-\mathrm{Hz}$ modulated field. These findings demonstrate that the radiomodulatory effects of RFF could be due to perturbations in DNA repair processes and cell cycle progression. Interaction between RFF and ionizing radiation might, thus, have important ramifications in radiotherapy, radiation protection, and wound healing in preoperative radiotherapy.

\section{ACKNOWLEDGMENTS}

This work is based on research supported in part by the National Research Foundation of South Africa (Grant Nos. 85703, 92741, 100157, 107703). Funding from the Faculty of Medicine and Health Sciences (Stellenbosch University), the Harry Crossley Foundation, and the Cancer Association of South Africa is also acknowledged.

\section{REFERENCES}

1. Miyakoshi J. Cellular and molecular responses to radio-frequency electromagnetic fields. Proc IEEE. 2013;101:1494-1502.

2. Elson E. Biologic effects of radiofrequency and microwave fields in vivo and in vitro experimental results. In: Bronzino JD, editor. The biomedical engineering handbook. Boca Raton, FL: CRC Press; 1995. p. 1417-23.

3. Zimmerman JW, Jimenez H, Pennison MJ, Brezovich I, Morgan D, Mudry A, Costa FP, Barbault A, Pasche B. Targeted treatment of cancer with radiofrequency electromagnetic fields amplitude-modulated at tumor-specific frequencies. Chin J Cancer. 2013;32:573-81.

4. Jimenez H, Blackman C, Lesser G, Debinski W, Chan M, Sharma S, Watabe K, Lo H-W, Thomas A, Godwin D, Blackstock W, Mudry A, Posey J, O’Connor R, Brezovich I, Bonin K, Kim-Shapiro D, Barbault A, Pasche B. Use of non-ionizing electromagnetic fields for the treatment of cancer. Front Biosci (Landmark Ed). 2018;23:284-97.

5. Chou C-K. Radiofrequency hyperthermia in cancer therapy. In: Bronzino JD, editor. The biomedical engineering handbook. Boca Raton, FL: CRC Press; 1995. p. 1424-30.

6. Chou C-K. Therapeutic heating applications of radio frequency energy. In: Barnes FS, Greenebaum B, editors. Handbook of biological effects of electromagnetic fields. Boca Raton, FL: CRC Press; 2007. p. 413-28.

7. Costa FP, de Oliveira AC, Meirelles R, Machado MCC, Zanesco T, Surjan R, Chammas MC, de Souza Rocha M, Morgan D, Cantor A, Zimmerman J, Brezovich I, Kuster N, Barbault A, Pasche B. Treatment of advanced hepatocellular carcinoma with very low levels of amplitude-modulated electromagnetic fields. Brit J Cancer. 2011;105:640-8.

8. Barbault A, Costa FP, Bottger B, Munden RF, Bomholt F, Kuster N, Pasche B. Amplitude-modulated electromagnetic fields for the treatment of cancer: Discovery of tumor-specific frequencies and assessment of a novel therapeutic approach. J Exp Clin Cancer Res. 2009;28:51.

9. Zimmerman JW, Pennison MJ, Brezovich I, Yi N, Yang CT, Ramaker R, Absher D, Myers RM, Kuster $\mathrm{N}$, Costa FP, Barbault A, Pasche B. Cancer cell proliferation is inhibited by specific modulation frequencies. Brit J Cancer. 2012;106:307-313.

10. Chinhengo A, Serafin A, Hamman B, Akudugu J. Electromagnetic fields induce frequency-dependent radioprotection and radiosensitization in in vitro cell cultures. Plasma Med. 2018;8:163-75.

11. Chinhengo A, Serafin A, Akudugu J. Comparison of cellular sensitivity to a split radiation dose and a combination of a single radiation dose and electromagnetic field exposure. Plasma Med. 2019;9:15-22.

Volume 10, Issue 1, 2020 
12. Bassen H, Litovitz T, Penafiel M, Meister R. ELF in vitro exposure systems for inducing uniform electric and magnetic fields in cell culture media. Bioelectromagnetics. 1992;13:183-98.

13. Akudugu JM, Slabbert JP, Serafin A, Böhm L. Frequency of radiation-induced micronuclei in neuronal cells does not correlate with clonogenic survival. Radiat Res. 2000;153:62-7.

14. Vijayalaxmi, Bisht KS, Pickard WF, Meltz ML, Roti JL, Moros EG. Chromosome damage and micronucleus formation in human blood lymphocytes exposed in vitro to radiofrequency radiation at a cellular telephone frequency (847.74 MHz, CDMA). Radiat Res. 2001;156:430-32.

15. Bisht KS, Moros EG, Straube WL, Baty JD, Roti JL. The effect of $835.62 \mathrm{MHz}$ FDMA or $847.74 \mathrm{MHz}$ CDMA modulated radiofrequency radiation on the induction of micronuclei in C3H 10T(1/2) cells. Radiat Res. 2002;157:506-15.

16. McNamee JP, Bellier PV, Gajda GB, Miller SM, Lemay EP, Lavallée BF, Marro L, Thansandote A. DNA damage and micronucleus induction in human leukocytes after acute in vitro exposure to a 1.9 GHz continuous-wave radiofrequency field. Radiat Res. 2002;158:523-33.

17. Koyama S, Nakahara T, Wake K, Taki M, Isozumi Y, Miyakoshi J. Effects of high frequency electromagnetic fields on micronucleus formation in CHO-K1 cells. Mutat Res. 2003;541:81-9.

18. Koyama S, Isozumi Y, Suzuki Y, Taki M, Miyakoshi J. Effects of 2.45-GHz electromagnetic fields with a wide range of SARs on micronucleus formation in CHO-K1 cells. Sci World J. 2004;20:29-40.

19. Bush C, McMillan TJ. Micronucleus formation in human tumour cells: Lack of correlation with radiosensitivity. Brit J Cancer. 1993;67:102-6.

20. Villa R, Zaffaroni N, Gornati D, Costa A, Silvestrini R. Lack of correlation between micronucleus formation and radiosensitivity in established and primary cultures of human tumours. Brit J Cancer. 1994;70:1112-7.

21. Theron T, Binder A, Verheye-Dua F, Böhm L. The role of G2-block abrogation, DNA double-strand break repair and apoptosis in the radiosensitization of melanoma and squamous cell carcinoma cell lines by pentoxifylline. Int J Radiat Biol. 2000;76:1197-1208.

22. Akudugu JM, Theron T, Serafin A, Böhm L. Influence of DNA double-strand break rejoining on clonogenic survival and micronucleus yield in human cell lines. Int J Radiat Biol. 2004;80:93-104.

23. Roos WP, Binder A, Böhm L. Determination of the initial DNA damage and residual DNA damage remaining after 12 hours of repair in eleven cell lines at low doses of irradiation. Int J Radiat Biol. 2000;76:1493-1500.

24. El-Awady RA, Dikomey E, Dahm-Daphi J. Radiosensitivity of human tumour cells is correlated with the induction but not with the repair of DNA double-strand breaks. Brit J Cancer. 2003;89:593-601.

25. Akudugu JM, Böhm L. Micronuclei and apoptosis in glioma and neuroblastoma cell lines and role of other lesions in the reconstruction of cellular radiosensitivity. Radiat Environ Biophys. 2001;40:295-300.

26. Akudugu J, Gäde G, Böhm L. Cytotoxicity of azadirachtin A in human glioblastoma cell lines. Life Sci. 2001;68:1153-60.

27. Akudugu JM, Bell RS, Catton C, Davis AM, O'Sullivan B, Waldron J, Wunder JS, Hill RP. Clonogenic survival and cytokinesis-blocked binucleation of skin fibroblasts and normal tissue complications in soft tissue sarcoma patients treated with preoperative radiotherapy. Radiother Oncol. 2004;72:103-12.

28. Velizarov S, Raskmark P, Kwee S. The effects of radiofrequency fields on cell proliferation are nonthermal. Bioelectrochem Bioenerg. 1999;48:177-80.

29. Marinelli F, La Sala D, Cicciotti G, Cattini L, Trimarchi C, Putti S, Zamparelli A, Giuliani L, Tomassetti G, Cinti C. Exposure to $900 \mathrm{MHz}$ electromagnetic field induces an unbalance between pro-apoptotic and pro-survival signals in T-lymphoblastoid leukemia CCRF-CEM cells. Cell Physiol. 2004;198:324-32.

30. Pacini S, Ruggiero M, Sardi I, Aterini S, Gulisano F, Gulisano M. Exposure to global system for mobile communication (GSM) cellular phone radiofrequency alters gene expression, proliferation, and morphology of human skin fibroblasts. Oncol Res. 2002;13:19-24.

31. Gurisik E, Warton K, Martin DK, Valenzuela SM. An in vitro study of the effects of exposure to a 
GSM signal in two human cell lines: Monocytic U937 and neuroblastoma SK-N-SH. Cell Biol Int. 2006;30:793-9.

32. Sanchez S, Milochau A, Ruffie G, Poulletier de Gannes F, Lagroye I, Haro E, Surleve-Bazeille JE, Billaudel B, Lassegues M, Veyret B. Human skin cell stress response to GSM-900 mobile phone signals. In vitro study on isolated primary cells and reconstructed epidermis. FEBS J. 2006;273:5491-5507.

33. Binder AB, Serafin AM, Böhm LJF. Abrogation of G2/M-phase block enhances the cytotoxicity of daunorubicin, melphalan and cisplatin in TP53 mutant human tumor cells. Radiat Res. 2000;154:640-9.

34. McIlwrath AJ, Vasey PA, Ross GM, Brown R. Cell cycle arrests and radiosensitivity of human tumor cell lines: Dependence on wild-type p53 for radiosensitivity. Cancer Res. 1994;54:3718-22.

35. Su L-N, Little JB. Prolonged cell cycle delay in radioresistant human cell lines transfected with activated ras oncogene and/or Simian virus 40 T-antigen. Radiat Res. 1993;133:73-9.

Volume 10, Issue 1, 2020 
